\title{
Monitoring food storage humidity and temperature data using loT
}

\begin{abstract}
In food industry, cold storage is a must. The main objective of this kind of storage is to preserving the raw foods within for a certain period of time. But, for lack of technology and ignorance about humidity and temperature effect on raw foods; many times, food safety is not maintained well enough. In this paper, the basic objective of this research is to mitigate the man monitoring and to develop an internet based real time monitoring of temperature and humidity using the very available DHT-11 sensor and ESP-8266 NodeMCU module. This paper also makes compact distinctions between conventional and the IoT based monitoring system of food storages.
\end{abstract}

Keywords: food safety, IoT, NodeMCU, digital cold storage, cloud service
Volume 6 Issue 4 - 2018

\author{
Asif Bin Karim, ' Md Zahid Hassan, ${ }^{2}$ Md \\ Masum Akanda, ${ }^{3}$ Avijit Mallik ${ }^{4}$ \\ 'Department of Mechatronics Engineering, Rajshahi University \\ of Engineering \& Technology, Bangladesh \\ ${ }^{2}$ Department of Industrial and Production Engineering, Rajshahi \\ University of Engineering \& Technology, Bangladesh \\ ${ }^{3}$ Department of Glass and Ceramics Engineering, Rajshahi \\ University of Engineering \& Technology, Bangladesh \\ ${ }^{4}$ Department of Mechanical Engineering, Rajshahi University of \\ Engineering \& Technology, Bangladesh
}

Correspondence: Avijit Mallik, Undergraduate Student, Department of Mechanical Engineering, Rajshahi University of Engineering \& Technology, Rajshahi- 6204, Bangladesh, Email avijitmel3@gmail.com

Received: July 31, 2018 | Published: August 10, 2018

\section{Introduction}

At present, IoT or Internet of Things has become a very popular choice for everyone. This is mainly because of the easy availability of internet, which helps us in many ways. Almost in every administrative or monitoring work internet is a must thing. So, this day's people want to control their many works through internet. For Food or Argo industries monitoring of the foods or materials which are rotten able are subject to constant monitoring; if just a simple thing goes wrong then it can become a result of a big loss. So, real time monitoring of foods/materials for those industries are very necessary. ${ }^{1-3}$ In this paper, a research has been carried out to monitor real-time condition (Humidity and Temperature to be more precise) through internet; in which physical presence is not needed. So, that can save man work and also a very effective way of monitoring. This research has been conducted using very simple methodology and appliances which are available and requires minimal technical knowledge to operate. DHT11 is a type of sensor which can detect the temperature and humidity of its near atmosphere and it's available in almost everywhere in the world. Combining the results with MATLAB environment, the upcoming data can be also forecasted through the basic knowledge of machine learning. Arduino is a really good and easy to use hardware this day, this has also an individual IDE named as the same hardware. But using an Arduino board is not necessary for just monitoring services, it is a waste of money and time. NodeMCU is a kind of module that consists an ESP8266 wifi along with a microcontroller with one analog and 12 digital pins, for which is more robust than an Arduino board. Our research is mainly based on NodeMCU for its compactness.

In 2000, just RFID labels were utilized to order the protest and steering. Furthermore, later the possibility of security, observation, transport supervision and medicinal services are arrived. The current circumstance is that we can without much of a stretch find each protest and people groups. This innovation headway can make more employment degrees and research thoughts. It is been anticipated that by 2020 , the PCs can perform like people to deal with the things. ${ }^{3-5}$ The unpredictability in sensors and association of numerous sensors in a framework has improved the information estimation, examination and furthermore information conglomeration in confined level. Sinha et al. proposed demonstrate includes of distinguishing units which sees the natural quality, (for illustration, Humidity, temperature, warm rundown, gas, et cetera), voltage and current parameters of the diverse family machines for watching the measure of power ate up. Also, a controlled structure yielded the amassed data by utilizing Xively IoT web benefit (Now gives trail form). ${ }^{3}$

An IoT based automation system focuses on controlling electronic devices whether being anywhere. ${ }^{4}$ Automation has the ability to control or monitor electronic devices remotely and in addition to the IoT cloud service, the devices can be controlled or monitored from anywhere just by connecting to the internet. Automation is today's fact, where things are being controlled automatically, usually the basic tasks of turning ON/OFF certain devices and beyond, either remotely or in close proximity. ${ }^{5}$

The Internet of Things (IoT) is the system of physical gadgets, vehicles, home apparatuses, and different things inserted with hardware, programming, sensors, actuators, and network which empowers these things to interface and trade information, making open doors for more straightforward joining of the physical world into PC based systems, bringing about proficiency enhancements, monetary advantages, and decreased human efforts. The quantity of IoT gadgets expanded multi year-over-year to 8.4 billion out of 2017 and it is assessed that there will be 30 billion gadgets by 2020 . The worldwide market estimation of IoT is anticipated to reach $\$ 7.1$ trillion by 2020 . IoT includes broadening web network past standard gadgets, for example, work areas, workstations, cell phones and tablets, to any scope of customarily idiotic or non-web empowered physical gadgets and regular items. Installed with innovation, these gadgets can convey and interface over the web, and they can be remotely observed and controlled. ${ }^{4-6}$ IoT includes expanding web availability past standard 
gadgets, for example, work areas, workstations, cell phones and tablets, to any scope of customarily stupid or non-web empowered physical gadgets and ordinary articles. Implanted with innovation, these gadgets can impart and associate over the web, and they can be remotely checked and controlled. Figure 1 shows the fundamental model of a 'Web of Things' based checking framework.'

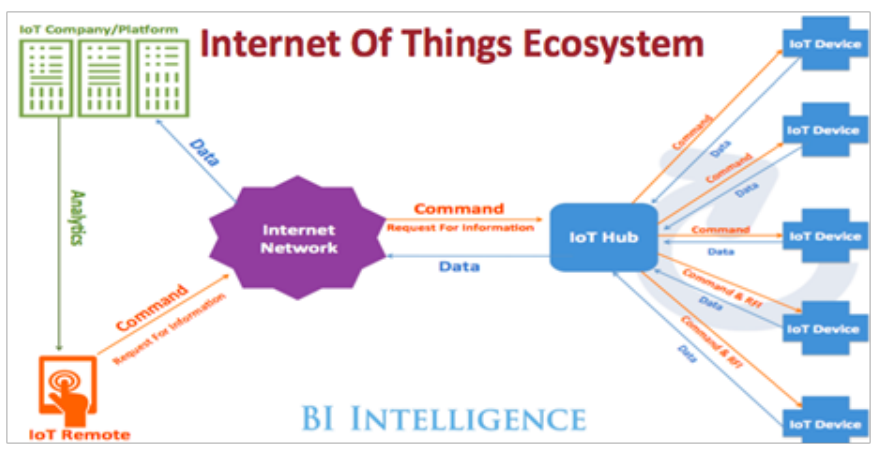

Figure I Internet of Things based monitoring service. ${ }^{4}$

Environmental monitoring applications of the IoT typically use sensors to assist in environmental protection by monitoring air or water quality, atmospheric or soil conditions, and can even include areas like monitoring the movements of wildlife and their habitats. Development of resource-constrained devices connected to the Internet also means that other applications like earthquake or tsunami early-warning systems can also be used by emergency services to provide more effective aid. IoT devices in this application typically span a large geographic area and can also be mobile. It has been argued that the standardization IoT brings to wireless sensing will revolutionize this area.

In semi-open or closed loops (i.e. value chains, whenever a global finality can be settled) IoT will often be considered and studied as a complex system due to the huge number of different links, interactions between autonomous actors, and its capacity to integrate new actors. At the overall stage (full open loop) it will likely be seen as a chaotic environment (since systems always have finality). As a practical approach, not all elements in the Internet of things run in a global, public space. Subsystems are often implemented to mitigate the risks of privacy, control and reliability. For example, domestic robotics (demotics') running inside a smart home might only share data within and be available via a local network. Figure 2 shows the road map of this IoT technology.

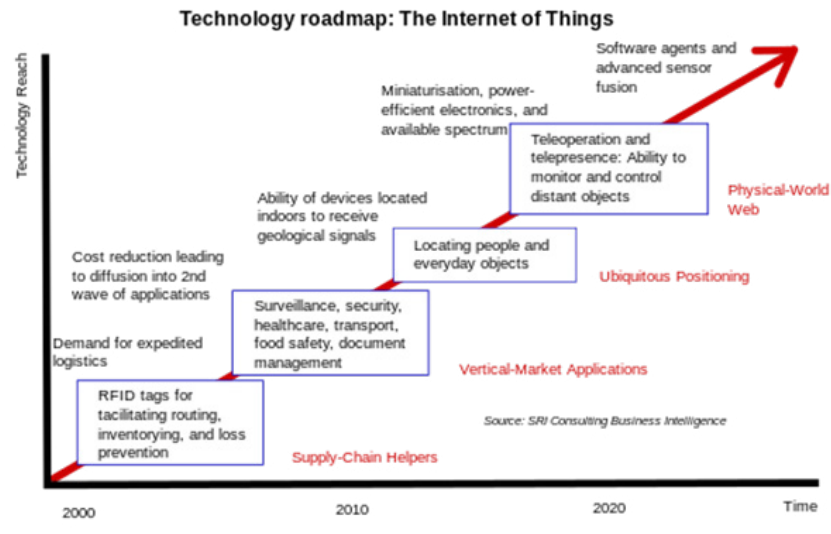

Figure 2 Technological roadmap of loT. ${ }^{5}$

\section{Materials and methods}

Materials: In this research the brand-new model of ESP-8266 aka NodeMCU was used. The various systems of IoT uses Arduino or Raspberry-pi as their mother controller but using NodeMCU gives the benefit of using an Arduino along with a $2.4 \mathrm{GHz}$ wifi module with a very robust look. As this was a demo project and need far more investigation in the real practice so, normal breadboards and jumper wires were used to test the functions. Figure 3 depicts the necessary materials used for this research.

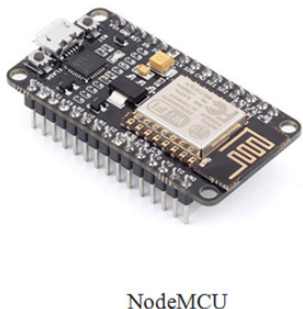

A

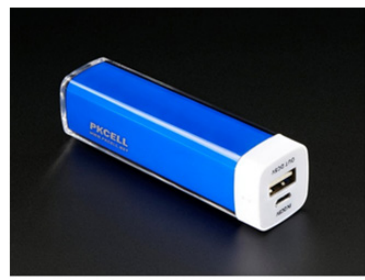

Power Bank of $5 \mathrm{~V}$ output D

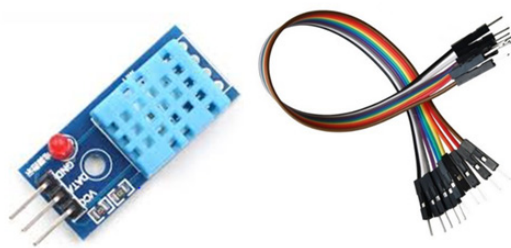

Jumper Wires
C

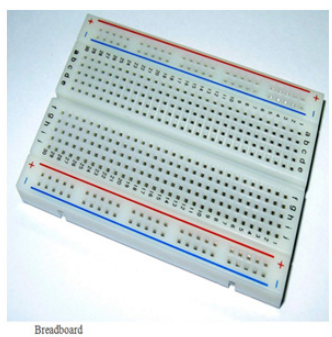

E

Figure 3 Necessary materials for the research work.

\section{Bill of materials}

The below Table 1 shows the BOM of this research. The calculations above show that the highest approximated cost to make this monitoring hardware is at most 700 BDT (equivalent to $8 \$$ ) which is not so costly and very easy to make.

Table I Bill of Materials (available from local markets of Bangladesh)

\begin{tabular}{lll}
\hline SI. No. & Name of component & Price (BDT) \\
\hline I & Breadboard/Veroboard & $45 / 23$ \\
2 & Jumper Wires (8-10 pcs) & 14 \\
3 & NodeMCU (Chinese clone) & 480 \\
4 & DHT-II Sensor (I pcs) & 130 \\
5 & 5V Battery (I pcs) & 45 \\
& Total Bill: & $692-714$ BDT \\
\hline
\end{tabular}

\section{Methodology}

The methodology is divided into two basic parts, hardware and software-based methodology. Firstly, the hardware setup was done. The connection between NodeMCU and DHT-11 sensor was done using conventional methods which is depicted in Figure 4 below.

Natural checking utilizations of the IoT commonly utilize sensors to aid ecological insurance by observing air or water quality, barometrical or soil conditions, and can even incorporate territories like observing the developments of untamed life and their living 
spaces. Improvement of asset obliged gadgets associated with the Internet additionally implies that different applications like seismic tremor or tidal wave early-cautioning frameworks can likewise be utilized by crisis administrations to give more compelling guide. IoT gadgets in this application normally traverse a substantial geographic region and can likewise be versatile. It has been contended that the institutionalization IoT conveys to remote detecting will reform this region.

In semi-open or shut circles (i.e. esteem chains, at whatever point a worldwide conclusion can be settled) IoT will frequently be considered and examined as a perplexing framework because of the colossal number of various connections, cooperation's between independent on-screen characters, and its ability to incorporate new performers. At the general stage (full open circle) it will probably be viewed as a disorderly situation (since frameworks dependably have irrevocability). As a reasonable approach, not all components in the Internet of things keep running in a worldwide, open space. Subsystems are regularly executed to relieve the dangers of security, control and unwavering quality. For instance, household mechanical technology (demotics') running inside a shrewd home may just share information inside and be accessible by means of a neighborhood organize. Figure 5 demonstrates the guide of this IoT innovation.

The site utilized is www.thingspeak.com. Record and channel must be made to get API key, which is essential to refresh new qualities to the diagram. Correspondence between board module and ThingSpeak is finished by utilizing AT charge. To send information, API key of ThingSpeak is expected to interface with ThingSpeak by order AT+CIPSTART. Sensor esteem must be changed over into string; henceforth information can be refreshed by utilizing charge AT + CIPSEND. After information is sent, association must be shut by AT+CIPCLOSE. Aside from sending the information to a free IoT web server, for example, thingspeak.com, similar information is additionally sent to neighborhood database and web server inside the Local Area Network. The major distinctive is just on the IP address, while at the same time the procedure of information securing and http ask for parcel development are almost the same. Information taking is a compulsory to check the unwavering quality of the module. Information taking can be led in two situations, indoor and open air, to know the affectability and unwavering quality of the module. The aggregate framework engineering is given in Figure 6 beneath.

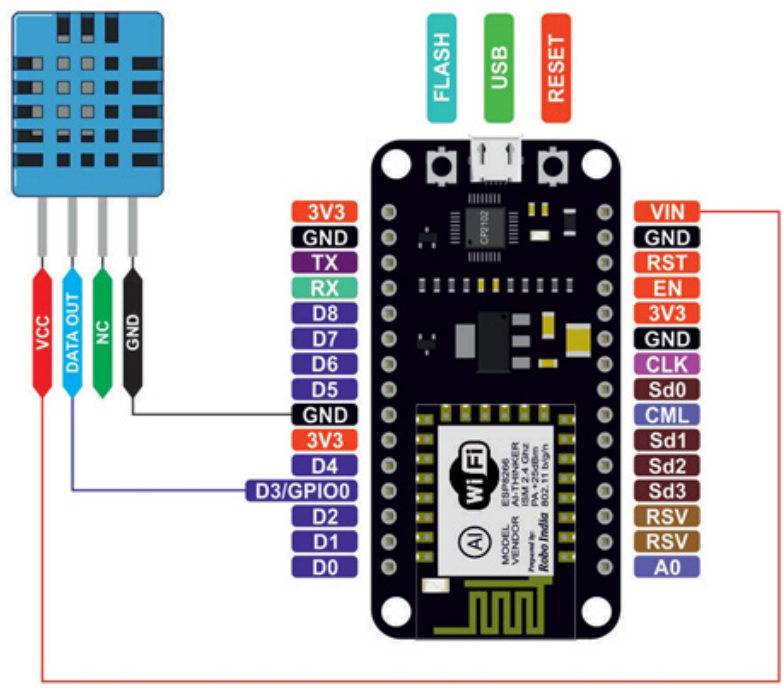

Figure 4 Connection between NodeMCU and DHT-I I sensor.

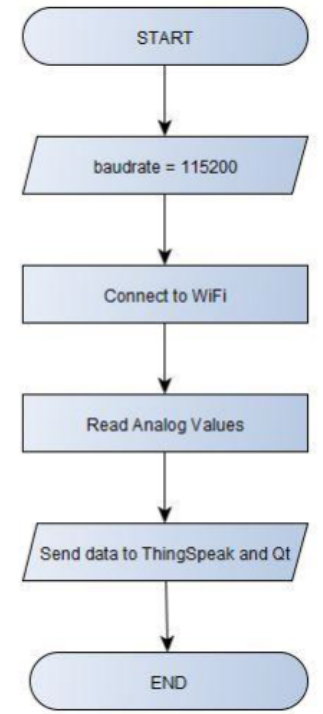

Figure 5 Flowchart of operation.
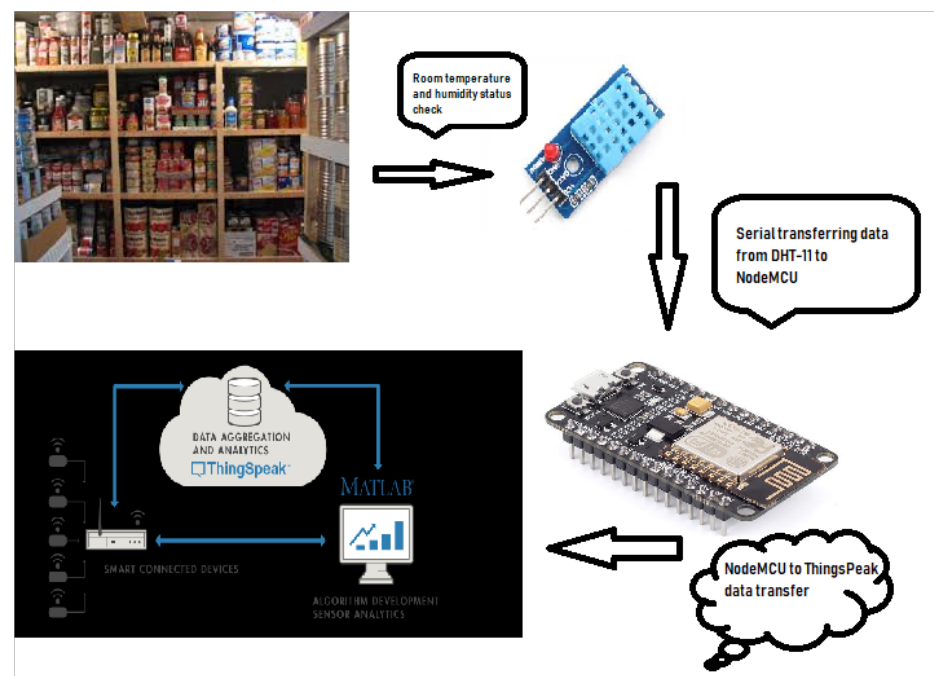

Figure 6 System architecture of the proposed system for food condition monitoring. 


\section{Results and discussions}

The results from the ThingsPeak channel were satisfactory and it needs just some milliseconds to transfer the Real-time data into the cloud service. Table 2 shows the data obtained from the ThingsPeak channel and the data from the NodeMCU serial monitoring. Just a few variations were observed.
From Table 2, a total reading of temperature and humidity is known for a 24 hour of experiment. Though some data were plotted arbitrarily, the experiment was a success and a satisfactory observation was made. Figure 7 shows the outputs and ThingsPeak GUI of this experiment.

Table 2 Data obtained from ThingsPeak and NodeMCU Serial monitor

\begin{tabular}{|c|c|c|c|c|c|c|c|c|}
\hline \multirow[b]{2}{*}{ Time } & \multicolumn{2}{|l|}{ Things peak } & \multicolumn{2}{|l|}{ Serial monitor } & \multicolumn{2}{|l|}{ Deviation } & \multicolumn{2}{|c|}{ Time delay (ms) } \\
\hline & $\begin{array}{l}\text { Temperature } \\
\left({ }^{\circ} \mathrm{C}\right)\end{array}$ & $\begin{array}{l}\text { Humidity } \\
\text { (\%) }\end{array}$ & $\begin{array}{l}\text { Temperature } \\
\left({ }^{\circ} \mathrm{C}\right)\end{array}$ & $\begin{array}{l}\text { Humidity } \\
\text { (\%) }\end{array}$ & Temperature & Humidity & Temperature & Humidity \\
\hline 10:30 AM & 31 & 62 & 31 & 62 & 0 & 0 & 0 & 0 \\
\hline $10: 35 \mathrm{AM}$ & 30.9 & 65 & 30.6 & 66 & 0.3 & -1 & I & 1.23 \\
\hline 10:40 AM & 31.3 & 63 & 31 & 62 & 0.3 & 1 & 0 & 3 \\
\hline I0:55 AM & 32 & 65 & 30.8 & 62 & 1.2 & 3 & 0 & 0 \\
\hline $\mathrm{II}: 20 \mathrm{AM}$ & 31 & 62 & 32.3 & 62 & -1.3 & 0 & 3 & 0 \\
\hline II:30 AM & 31 & 62 & 31 & 62 & 0 & 0 & 1 & 2 \\
\hline I2:00 PM & 33 & 49 & 35 & 55 & -2 & -6 & 0 & 0 \\
\hline I:00 PM & 33 & 52 & 33 & 55 & 0 & -3 & 0 & 2 \\
\hline 2:00 PM & 33 & 48 & 33 & 50 & 0 & -2 & I & 0 \\
\hline 3:00 PM & 31 & 42 & 31 & 43 & 0 & -1 & 0 & 0 \\
\hline 7:00 PM & 30 & 49 & 28 & 50 & 2 & -1 & 0 & 0 \\
\hline 9:30 PM & 30 & 55 & 30.2 & 55 & -0.2 & 0 & 0 & 0 \\
\hline 10:00 PM & 31 & 39 & 31 & 39 & 0 & 0 & 4 & 2 \\
\hline I0:30 PM & 30 & 40 & 29.4 & 40 & 0.6 & 0 & 2 & 2 \\
\hline
\end{tabular}

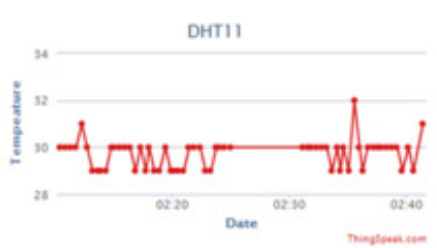

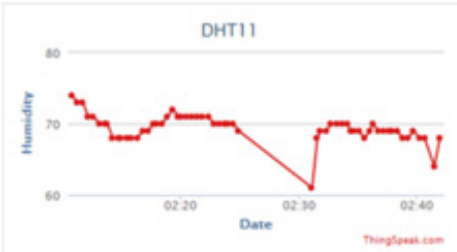

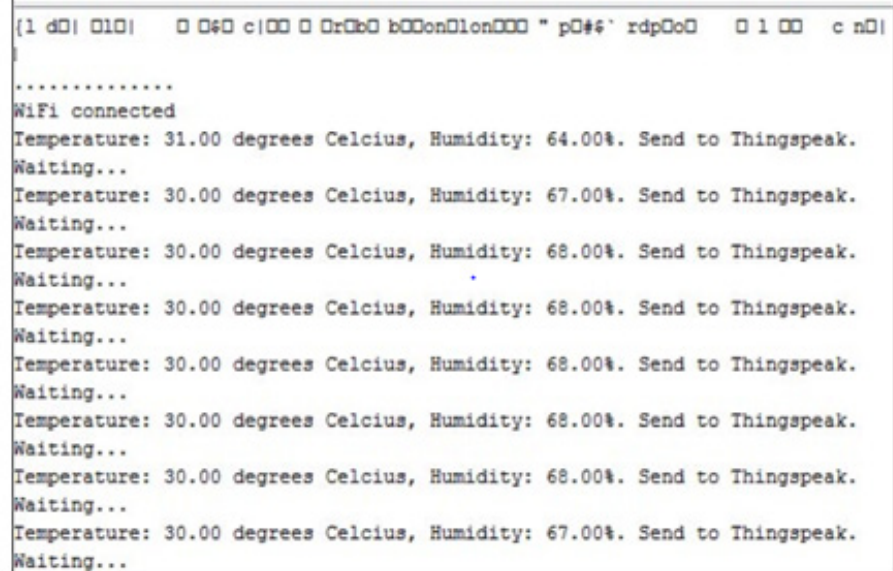

C

Figure 7 A Temperature Data GUI from ThingsPeak. B Humidity Data GUI from ThingsPeak. C NodeMCU serial monitor GUI. 


\section{Conclusion}

The experimentation was a success and from this experimentation we can understand how to measure the temperature and humidity data of a space. By using this automated system in a cold storage, we can evaluate and monitor the various data by our mobile phone or via PC's. If any abruption takes place then it can be also made automated to turn on/off any external relay module which can operate/condition the temperature and humidity inside a cold storage.

\section{Acknowledgements}

The author would like to thank all the teachers of the dept. of Mechanical Engineering for giving them all the necessary supports and special thanks goes to Dr. Mhia Md. Zaglul Shahadat for always giving rightful instructions.

\section{Authors' Contributions}

This works was a part of the self-funded project on 'Environmental systems automation and control' by the $4^{\text {th }}$ author and was directly done by the first three authors under the supervision of the $4^{\text {th }}$ author.

\section{References}

1. Pasha S. ThingSpeak based sensing and monitoring system for IoT with Matlab Analysis. International Journal of New Technology and Research (IJNTR). 2016;2(6):19-23.

2. Mhatre L, Rai N. Integration between wireless sensor and cloud. In: I-SMAC (IoT in Social, Mobile, Analytics and Cloud) (I-SMAC). IEEE. 2017:779-782.

3. Sinha N, Pujitha KE, Alex JSR. Xively based sensing and monitoring system for IoT. Computer Communication and Informatics (ICCCI). 2015:1-6.

4. What is the Internet of Things (IoT)?

5. IoT.

6. Environmental Statistics and the Consequences That Affect the Future of the Earth. 2011.

7. Zhao S, Yu L, Cheng B, et al. IoT Service Clustering for Dynamic Service Matchmaking. Sensors. 2017;17(8):1727. 